\title{
Effect of single-dose invermectin therapy on human Onchocerca volvulus infection with onchocercal ocular involvement
}

\author{
HENRY S NEWLAND,' ALBERT T WHITE,'2 BRUCH M GREENE, 2 \\ SALVATORE A D'ANNA,' EZATOLLAH KEYVAN-LARIJANI,' \\ MOHAMMED A AZIZ, ${ }^{3}$ P NOEL WILliAMS, AND HUGH R TAYLOR'
}

From the 'Ocular Onchocerciasis Research Unit, International Centre for Epidemiologic and Preventive Ophthalmology, the Wilmer Institute, Johns Hopkins University, Baltimore, Maryland; the ${ }^{2}$ Division of Geographic Medicine, Department of Medicine, Case Western Reserve University and University Hospitals, Cleveland, Ohio; ${ }^{3}$ Merck, Sharp and Dohme Research Laboratories; Rahway, New Jersey, USA; and Uniroyal Liberian Agricultural Company, Grand Bassa County, Liberia

SUMMARY Ivermectin has shown promise as a potentially safe and effective microfilaricidal drug for the treatment of onchocerciasis. Several limited studies have shown it to have fewer side effects, especially ocular complications, than the currently available drug, diethylcarbamazine. The detailed ocular findings in 200 moderately to heavily infected Liberians who were enrolled in a safety and dose-finding study are presented. They received either $0,100,150$, or $200 \mu \mathrm{g} / \mathrm{kg}$ of ivermectin and were followed up for 12 months. In clinical studies so far carried out ivermectin in a dose of 100,150 , or $200 \mu \mathrm{g} / \mathrm{kg}$ has not been associated with any major adverse reactions nor were there any sight-threatening effects even in the presence of severe ocular disease. Each of these doses significantly reduced the ocular microfilaria load for at least 12 months when compared with either the placebo $(\mathrm{p}<0.05)$ or pretreatment values $(\mathrm{p}<0.001)$. However, the 100 and $150 \mu \mathrm{g} / \mathrm{kg}$ doses caused fewer minor side effects than the higher dose. These results confirm that ivermectin in a single oral dose may be a safe and effective microfilaricidal drug for the treatment of onchocerciasis and that it appears to be free of major ocular side effects.

No appropriate treatment is available for widespread use against onchocerciasis. The two drugs used, diethylcarbamazine (DEC) and suramin, are associated with severe systemic and ocular side effects. The ocular side effects of DEC are well known and include permanent sight-threatening changes and sometimes blindness. ${ }^{1-6}$ DEC is therefore recommended only for patients with severe disease, especially those whose sight is severely threatened without treatment. ${ }^{78}$ Suramin, which is inherently toxic, ${ }^{9}$ also causes similar ocular changes. ${ }^{10}$ Invermectin, a semisynthetic macrocyclic lactone widely used in veterinary medicine, shows promise as a microfilaricidal drug that has been better tolerated than

Correspondence to Hugh R Taylor, MD, 116 Wilmer Building, Johns Hopkins Hospital, 600 North Wolfe Street, Baltimore, Maryland 21205, USA.
DEC and has fewer ocular complications in the studies conducted so far. ${ }^{11-19}$

Studies of invermectin treatment in man that have been reported so far are limited to fewer than 100 patients, most of whom had either relatively mild disease or incomplete follow-up. We report here the detailed ocular findings of a double masked study of dosage and efficacy in which 200 patients with moderate to severe onchocerciasis were treated with one of three different doses of invermectin or placebo. The detailed systemic findings in this group of patients are being reported separately. ${ }^{19}$

\section{Subjects and methods}

SUBJECTS

Eight hundred patients, aged $12-60$ years, were screened clinically and parasitologically. The 200 
patients with heaviest infection by microfilaria skin count who were otherwise apparently healthy and who had given consent were selected for inclusion in this study. All patients had screening skin-snip microfilaria counts of greater than 15 microfilaria per $\mathrm{mg}$ of skin. Pregnant and lactating females and any subject who had received an antifilaricidal within one year were excluded." They were residents of the Liberian Agricultural Company rubber plantation in Grand Bassa County, Liberia, an area hyperendemic for the rain forest type of onchocerciasis.

\section{CLINICAL EVALUATION}

The patients underwent detailed ocular, physical, and parasitological examination before the start of treatment. ${ }^{19}$ The ocular examination included the testing of visual acuity with an illiterate $E$ chart and visual fields with a clear dome perimeter using a $2 \mathrm{~mm}$ fibreoptic target (Goodlite Company, Forest Park, Illinois).

The anterior chamber and cornea were examined with a Topcon SL5D slit-lamp at $25 \times$ after the subjects were placed in the head down position for at least two minutes. The microfilariae in the cornea and the anterior chamber of each eye were counted. Limbitis was diagnosed by the presence of limbal vessel dilatation, limbal oedema, and white globular opacities, and each sign was graded as absent, mild, moderate, or severe. Anterior uveitis was diagnosed by the presence of anterior chamber cells and flare; each sign was graded as absent, mild, moderate, or severe. Sclerosing keratitis was graded according to the presence of limbal haze, the extent of characteristic corneal involvement starting in the nasal or temporal periphery, being confluent inferiorly, or covering the pupil. Intraocular pressure was measured by applanation tonometry.

The fundus was examined by direct and indirect ophthalmoscopy after pupil dilatation with $1 \%$ tropicamide and $10 \%$ phenylephrine hydrochloride. Fundus photography was performed with a Topcon FE fundus camera; the photographs were graded in a masked fashion with the patient's identity, treatment, and date of examination obscured. These photographs were graded for the presence and extent of intraretinal deposits, intraretinal pigment (IRP), atrophy of the retinal pigment epithelium (RPEA), retinitis, haemorrhage, optic neuropathy, and subretinal fibrosis. ${ }^{17}$ Intraretinal deposits are either small white or glistening deposits found in the neuroretina. They could be clearly distinguished in stereo photographs from drusen, which occur at the level of the retinal pigment epithelium. They had a different appearance from intraretinal microfilariae and in our experience do not occur in people living outside areas where onchocerciasis is endemic.
After treatment the detailed ocular examination was repeated at day 3 , and at three, six, and 12 months; physical and parasitological examinations were also repeated at these times. In order to quantify the ocular changes due to onchocerciasis and due to therapy an ocular reaction index was calculated." This index is based on the intraocular microfilaria load and the severity of punctate keratitis, limbitis, and anterior uveitis.

All subjects were admitted to hospital during the first four days of the study. One hundred and thirtytwo patients attended all follow-up examinations. The patients that missed one or more follow-up examinations included eight from the $100 \mu \mathrm{g} / \mathrm{kg}$, 17 from the $150 \mu \mathrm{g} / \mathrm{kg}, 16$ from the $200 \mu \mathrm{g} / \mathrm{kg}$ ivermectin groups, and 17 from the placebo group. There were 177 subjects present at three months, 162 at six months, and 176 at 12 months. At 12 months all patients not examined were accounted for as follows: 14 had moved to the interior of the country; six had moved to urban areas and could not be found; the whereabouts of one was unknown; and two refused examination. One patient in the $150 \mu \mathrm{g} / \mathrm{kg}$ group died of undetermined causes between the six- and 12month examination.

\section{TREATMENT PROTOCOL}

Subjects were randomly assigned to receive either () (placebo), 100, 150, or $200 \mu \mathrm{g} / \mathrm{kg}$ of ivermectin. The dosage was adjusted for weight, with $5 \mathrm{~kg}$ increments. The drug was provided in coded packages containing five identical capsules; each patient was treated individually and closely observed to ensure compliance. Additional medication was available on demand and included aspirin for pain or fever and antihistamine for pruritus or insomnia.

DATA ANALYSIS

Data were gathered in a double-masked fashion and entered for computer analysis prior to breaking the treatment code at six months. The patients were examined at 12 months without reference to the treatment code. Statistical analyses were based on analysis of covariance (to adjust for differences at baseline), with the two-tailed $t$ test for multiple comparisons $^{21}$ when means for treatment were compared. In addition the mean differences between groups over time were compared by simple $t$ test for independent samples. Other analyses were performed with Student's $t$ test or Fisher's exact test. The data analysis to be presented was performed on data available for all those patients present at an examination, regardless or their presence at other examinations. Restricting the analysis to only those patients present at every examination (132 or $66 \%$ ) did not alter the findings. 


\section{Results}

\section{PRETREATMENT FINDINGS}

Random assignment of the subjects into four groups resulted in similar distributions with regard to age, skin microfilaria count, and ocular findings (Table 1). Similarly, weight, number of palpable onchocercal nodules, and skin changes due to onchocerciasis were also evenly distributed. ${ }^{15}$

Thirty-two patients entered the study with visual acuity in one or both eyes of 6/12 or less. Of these, 17 had visual impairment (vision of less than $6 / 18$ in the worse eye). Eight subjects had abnormal visual fields. Their distribution was likewise similar among the treatment groups. Four patients, two in the 100 and one each in the 150 and $200 \mu \mathrm{g} / \mathrm{kg}$ groups, had unilateral optic atrophy.

One patient, a 13-year-old girl in the $200 \mu \mathrm{g} / \mathrm{kg}$ group, had active retinitis and optic neuritis in her only seeing eye, with severe bilateral anterior uveitis and raised intraocular pressure $(34 \mathrm{mmH}$ in each eye). This was associated with a massive intraocular microfilaria load (over 100 microfilariae in each anterior chamber). No evidence for other causes of severe intraocular inflammation, such as old toxoplasmosis lesions, could be seen.

\section{CHANGES AFTER THERAPY}

The mean skin microfilaria density in the three invermectin treatment groups was significantly reduced at all follow-up examinations in comparison with the placebo group $(\mathrm{p}<0 \cdot 01$, Table 2$)$. The rapid lowering of skin microfilariae in the first three days

Table 1 Pretreatment characteristics and prevalence of ocular findings

\begin{tabular}{|c|c|c|c|c|}
\hline \multirow[t]{2}{*}{ Finding } & \multicolumn{4}{|c|}{ Ivermectin treatment groups } \\
\hline & $\begin{array}{l}\text { Placebo } \\
(n=48)\end{array}$ & $\begin{array}{l}100 \mu g / k g \\
(n=49)\end{array}$ & $\begin{array}{l}150 \mu g / k g \\
(n=52)\end{array}$ & $\begin{array}{l}200 \mu \mathrm{g} / \mathrm{kg} \\
(n=51)\end{array}$ \\
\hline Mean age (years) & $30 \cdot 5$ & $29 \cdot 3$ & $29 \cdot 3$ & $30 \cdot 3$ \\
\hline \\
\hline $\begin{array}{l}\text { skin counts } \\
\text { (geometric mean, } \\
\text { mf/mg skin) }\end{array}$ & $21 \cdot 0$ & $17 \cdot 9$ & $21 \cdot 2$ & $20 \cdot 8$ \\
\hline Punctate keratitis & $\begin{array}{l}21^{*} \\
(43 \cdot 8 \%)\end{array}$ & $\begin{array}{l}15 \\
(30 \cdot 6 \%)\end{array}$ & $\begin{array}{l}21 \\
(40 \cdot 4 \%)\end{array}$ & $\begin{array}{l}22 \\
(43 \cdot 1 \%)\end{array}$ \\
\hline $\begin{array}{l}\text { Microfilariae in } \\
\text { cornea }\end{array}$ & $\begin{array}{l}16 \\
(33 \cdot 3 \%)\end{array}$ & $\begin{array}{c}8 \\
(16 \cdot 3 \%)\end{array}$ & $\begin{array}{l}15 \\
(28 \cdot 8 \%)\end{array}$ & $\begin{array}{l}14 \\
(27 \cdot 5 \%)\end{array}$ \\
\hline $\begin{array}{l}\text { Microfilariae in } \\
\text { anterior chamber }\end{array}$ & $\begin{array}{l}26 \\
(54 \cdot 2 \%)\end{array}$ & $\begin{array}{l}19 \\
(38 \cdot 8 \%)\end{array}$ & $\begin{array}{l}27 \\
(51 \cdot 9 \%)\end{array}$ & $\begin{array}{l}24 \\
(47 \cdot 1 \%)\end{array}$ \\
\hline Anterior uveitis & $\begin{array}{l}0 \\
(0 \cdot 0 \%)\end{array}$ & $\begin{array}{l}2 \\
(4 \cdot 1 \%)\end{array}$ & $\begin{array}{l}1 \\
(1.9 \%)\end{array}$ & $\begin{array}{l}1 \\
(2 \cdot 0 \%)\end{array}$ \\
\hline Limbitis & $\begin{array}{c}5 \\
(10 \cdot 4 \%)\end{array}$ & $\begin{array}{c}6 \\
(12 \cdot 2 \%)\end{array}$ & $\begin{array}{l}5 \\
(9 \cdot 6 \%)\end{array}$ & $\begin{array}{c}7 \\
(13 \cdot 7 \%)\end{array}$ \\
\hline Sclerosing keratitis & $\begin{array}{l}1 \\
(2 \cdot 1 \%)\end{array}$ & $\begin{array}{c}1 \\
(2 \cdot 0 \%)\end{array}$ & 2 & $\begin{array}{l}3 \\
(5 \cdot 9 \%)\end{array}$ \\
\hline
\end{tabular}

*Number affected (percentage).
Table 2 Microfilaria skin densities before and after treatment

\begin{tabular}{lllll}
\hline \multicolumn{5}{l}{ Microfilaria skin count } \\
\cline { 2 - 5 } & $\begin{array}{l}\text { Placebo } \\
(n=48)\end{array}$ & $\begin{array}{l}100 \mu g / \mathrm{kg} \\
(n=49)\end{array}$ & $\begin{array}{l}150 \mu \mathrm{g} / \mathrm{kg} \\
(n=52)\end{array}$ & $\begin{array}{l}200 \mu \mathrm{g} / \mathrm{kg} \\
(n=51)\end{array}$ \\
\hline Pretreatment & 21.0 & 17.9 & $21 \cdot 2$ & $20 \cdot 8$ \\
3 day & 17.7 & 7.0 & 7.00 & 4.3 \\
3 months & 16.5 & 0.93 & 0.65 & 0.55 \\
6 months & 15.6 & 1.8 & 1.7 & 1.3 \\
1 year & 13.0 & 3.1 & 3.5 & 3.6 \\
\hline
\end{tabular}

* Geometric mean for all those present at an examination $(\mathrm{mf} / \mathrm{mg}$ skin). All treatment groups had significant reduction in microfilaria densities at every interval compared to both placebo and to pretreatment levels $(\mathrm{p}<0 \cdot 01)$.

after treatment was associated with only mild systemic reactions. ${ }^{19}$

All patients in the ivermectin groups either retained the same visual acuity or improved, but one patient in the placebo group lost some vision in one eye (6/6 to 6/9) when tested at three and 12 months. No cause could be ascribed to this loss of vision. No patient suffered further loss of visual field at any of the follow-up examinations. The 13-year-old girl with active retinitis and neuritis at baseline was treated with intensive topical anti-inflammatory and pressure-lowering drugs in addition to ivermectin. She regained visual field, which enlarged from $10^{\circ}$ at baseline to $20^{\circ}$ at three months. There was no progression of optic atrophy in any patient in either the ivermectin or the placebo treated groups, and no new cases of optic neuritis or optic atrophy were seen at any follow-up examination.

The number of microfilariae in the anterior chamber in all treatment groups fell rapidly during the three days following treatment. At three months the difference between the ivermectin treated groups and the placebo group was significant, and it remained significant at the six- and 12-month examinations $(p<0 \cdot 05$, Fig. 1). The motility of microfilariae in the anterior chamber was observed to be abnormal for the first three days after ivermectin treatment. This abnormal motility consisted of a characteristic extended configuration, periodic immobility, and an occasional unusual motion in which the microfilariae bent only in the middle, suggestive of a spastic paralysis.

The number of corneal microfilariae in all treatment groups tended to increase by day 3 but had significantly decreased in the ivermectin treated groups at three months in comparison to the placebo group $(p<0 \cdot 01)$. As with the microfilariae counts in the skin, there was a gradual increase in the number of corneal microfilariae in the ivermectin treated groups between both the three- and six-month 
Fig. 1 Geometric mean number of microfilariae in anterior chamber in each treatment group. Asterisks indicate counts significantly different from those in placebo group (single asterisks, $p<0 \cdot 05$; double asterisks, $p<0 \cdot 01$ (t test)).

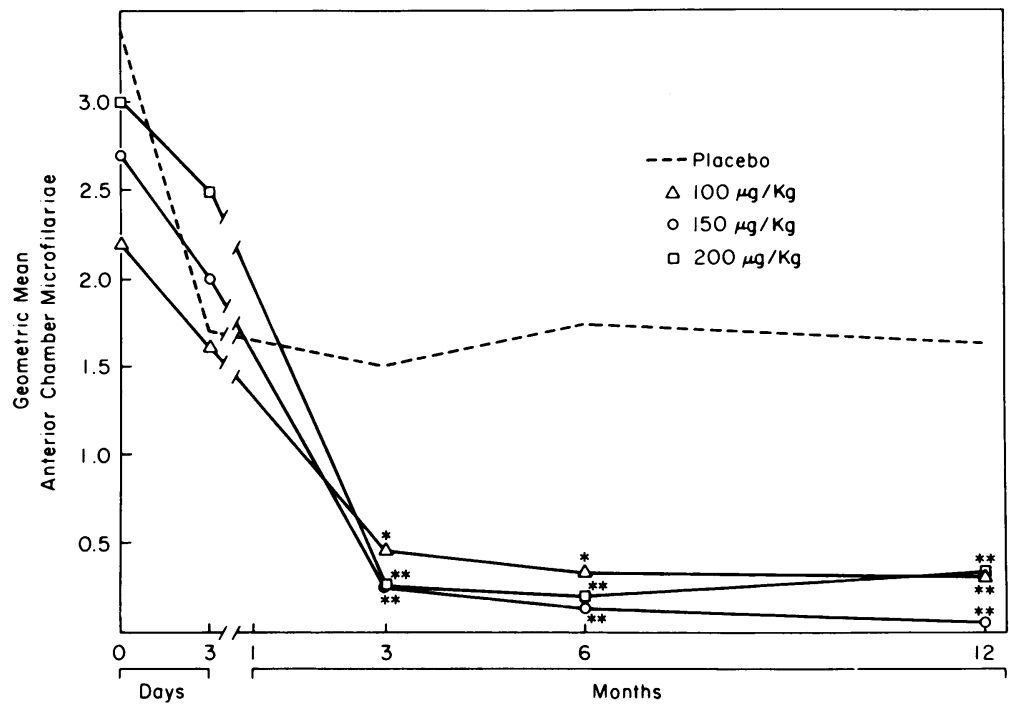

examinations and the twelve-month examination. Though not statistically significant, this was more marked in the $200 \mu \mathrm{g} / \mathrm{kg}$ group (Fig. 2). Similar changes were seen in the number of punctate corneal opacities; the $200 \mu \mathrm{g} / \mathrm{kg}$ group showed a small decrease at day three and a more marked (though not statistically significant) increase than the other invermectin groups at both the six-and 12-month examinations (Fig. 3).

In all three ivermectin groups there was a significant decrease in the ocular reaction index in comparison with the placebo group at three, six, and 12 months. There was no significant difference between the three ivermectin groups (Fig. 4).

Chorioretinal abnormalities were noted before and after treatment in patients in all treatment groups (Table 3). Patients were classified by their worse eye. In all instances the chorioretinal changes after treatment were noted to have occurred between the threeand 12-month examination. There was no change in the amount or distribution of IRP in patients with IRP from the ivermectin groups except in one patient in the $100 \mu \mathrm{g} / \mathrm{kg}$ group, in whom progressive IRP clumping was noted (Figs. 5A, B). All those with
Fig. 2 Geometric mean number of corneal microfilariae in each treatment group. Asterisks indicate counts significantly different than those in placebo group (single asterisks, $p<0.05 ;$ double asterisks, $p<0.01$ (t test)).

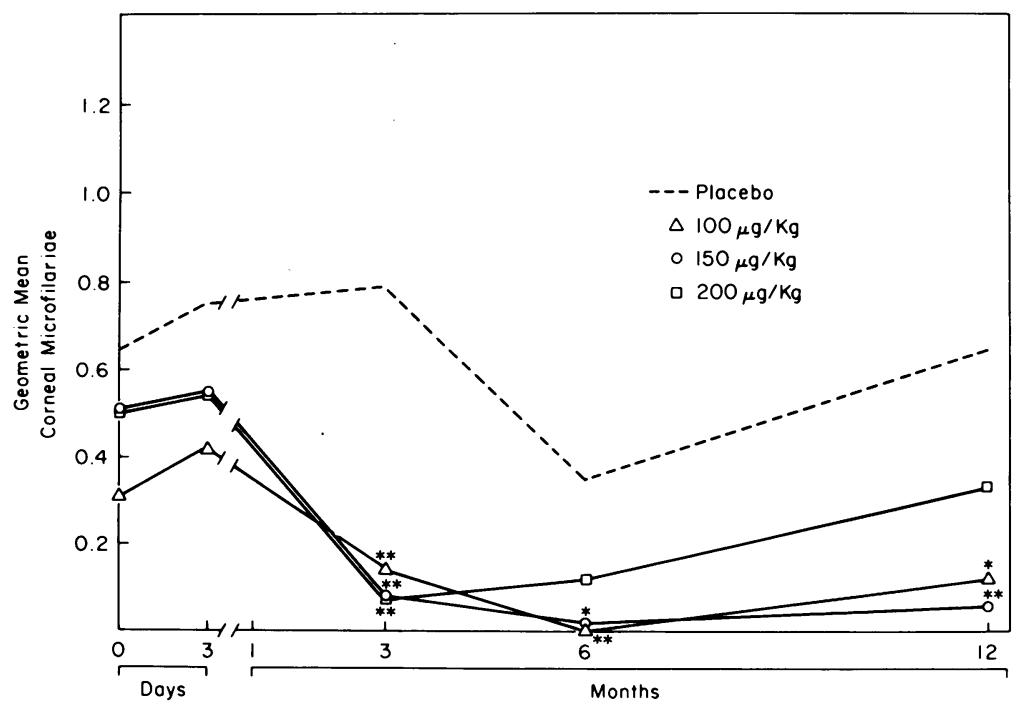




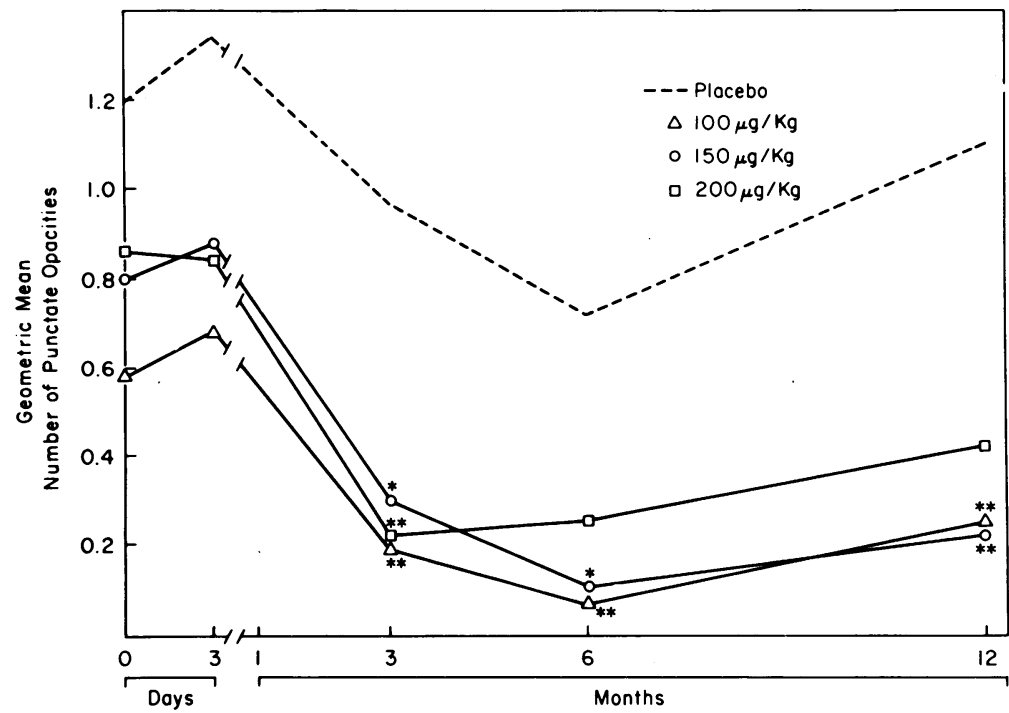

Fig. 3 Geometric mean number of punctate corneal opacities in each treatment group. Asterisks indicate counts significantly different from those in placebo group (single asterisks, $p<0.05$; double asterisks, $p<0 \cdot 01(\mathrm{t}$ test $))$.

RPEA in the ivermectin-treated groups remained unchanged (Fig. 6). In contrast, in the placebo group patients with either IRP or RPEA showed progression in $18.2 \%$ (four patients) and $23.1 \%$ (three patients) of cases respectively. Of patients initially without RPEA none of the ivermectin and $11.4 \%$ (four patients) of the placebo patients developed these changes. Nineteen patients with normal fundi before treatment developed retinal deposits, and they were from all four treatment groups. The proportion of patients who developed retinal deposits in the placebo group (seven patients) was significantly greater than that (one patient) in the 200 $\mu \mathrm{g} / \mathrm{kg}$ group $(\mathrm{p}<0.05)$. In two patients - a placebo patient and one from the $200 \mu \mathrm{g} / \mathrm{kg}$ group-with preexisting retinal deposits the number of deposits decreased after treatment.

The one patient with active retinitis and optic neuritis from the $200 \mu \mathrm{g} / \mathrm{kg}$ group (the 13-year-old girl mentioned above) showed some improvement clinically when seen at three days and three months, after which she was lost to further follow-up. One patient in the placebo group had a small area of mild retinitis which remained unchanged throughout the

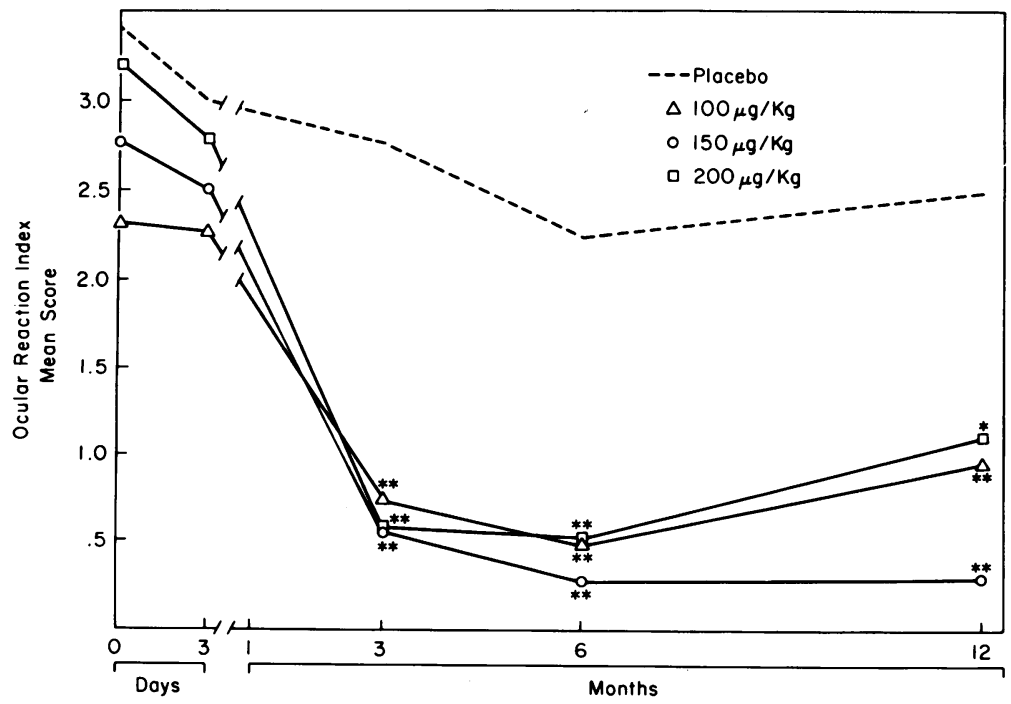

Fig. 4 Ocular reaction index in each treatment group. Asterisks indicate scores significantly different from those in placebo group (single asterisks, $p<0 \cdot 05$; double asterisks, $p<0.01$ (t test)). 


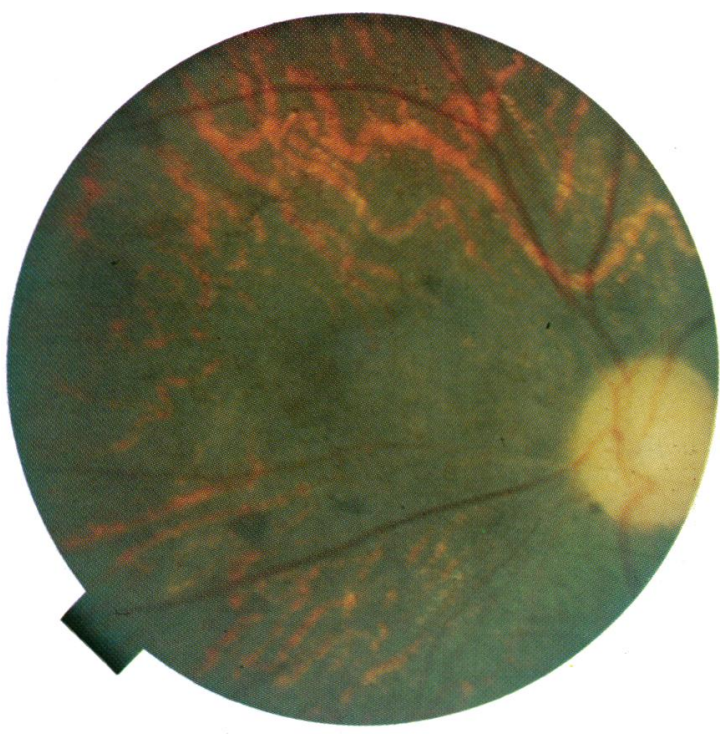

Fig. 5A

study (Fig. 7). A retinal haemorrhage appeared at three months in a placebo patient but had resolved by the six-month assessment (Fig. 8), while a small paramacular area of active retinitis in another patient on placebo remained unchanged during the study.

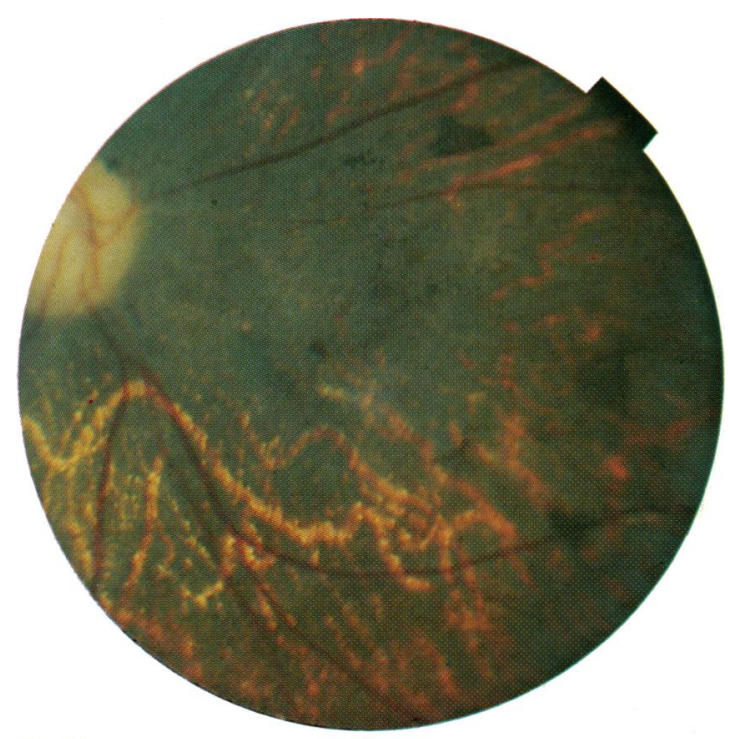

Fig. 5B

Fig. 5 Fundus photograph of 28-year-old female patient in the $100 \mu \mathrm{g} / \mathrm{kg}$ group before treatment (A) and six months after treatment $(\mathrm{B})$ in whom there was progressive intraretinal pigment clumping.

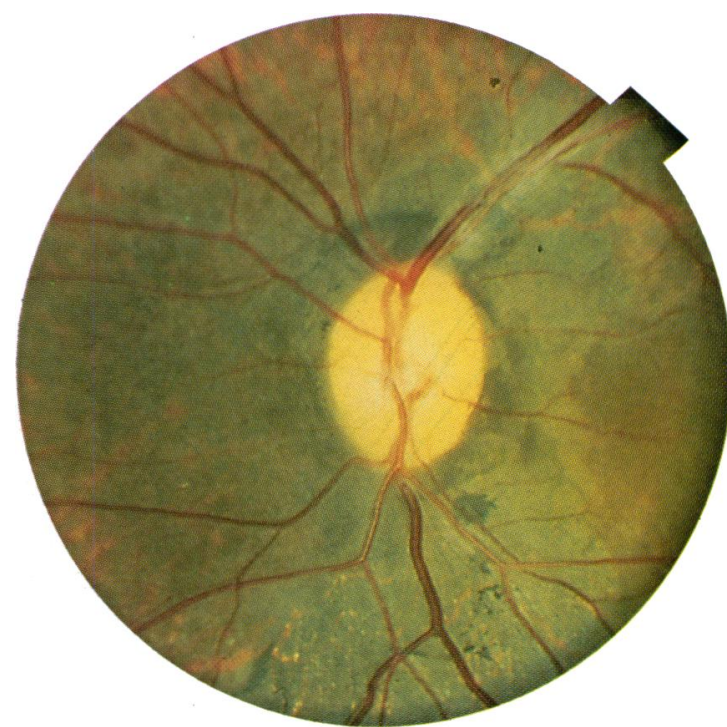

Fig. 6 Fundus photograph of 19-year-old male patient in the $100 \mu \mathrm{g} / \mathrm{kg}$ group showing retinal pigment epithelial atrophy and white retinal deposits (arrows below disc). Note also intraretinal pigment clumping superonasal to disc.

\section{Discussion}

This report presents the detailed ocular findings in a double-masked study of the safety and dosage of ivermectin comparing three different doses with

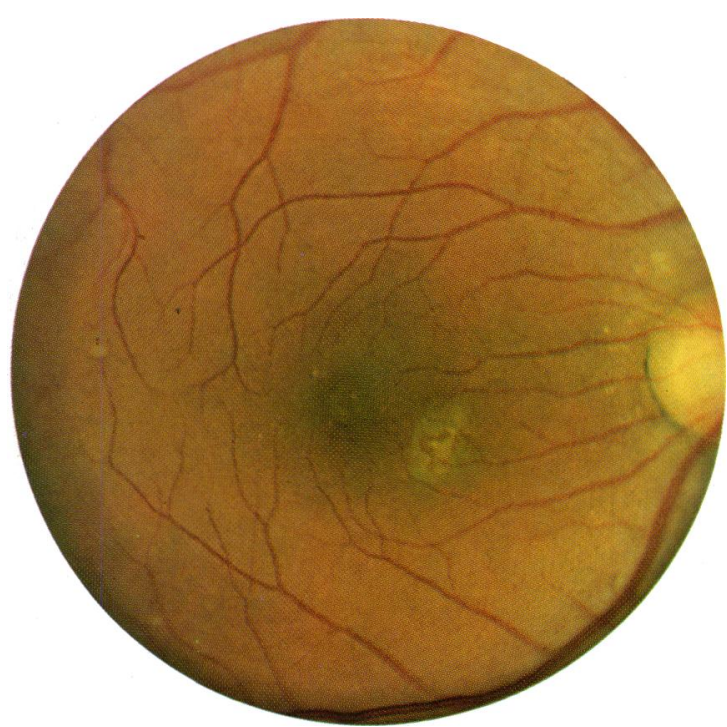

Fig. 7 Fundus photograph of a 48-year-old male placebo patient who received placebo showing a small area of mild retinitis which did not progress during the study. 
Table 3 Alteration in fundus findings according to pretreatment status during one-year follow-up

\begin{tabular}{|c|c|c|c|c|c|c|}
\hline \multirow{3}{*}{$\begin{array}{l}\text { Abnormali } \\
\text { /treatment } \\
\text { group }\end{array}$} & \multicolumn{6}{|c|}{$y$ Pretreatment status } \\
\hline & \multicolumn{2}{|c|}{$\begin{array}{l}\text { Abnormality } \\
\text { absent }\end{array}$} & \multicolumn{4}{|c|}{ Abnormality present } \\
\hline & No. & $\begin{array}{l}\% \\
\text { Worse }\end{array}$ & No. & $\begin{array}{l}\% \\
\text { Improved }\end{array}$ & $\begin{array}{l}\% \\
\text { No change }\end{array}$ & $\begin{array}{l}\% \\
\text { Worse }\end{array}$ \\
\hline \multicolumn{7}{|c|}{ Intraretinal pigment } \\
\hline Placebo & 26 & $0 \cdot 0$ & 22 & $0 \cdot 0$ & $81 \cdot 8$ & $18 \cdot 2$ \\
\hline $100 \mu \mathrm{g} / \mathrm{kg}$ & 32 & 0.0 & 17 & $0 \cdot 0$ & $100 \cdot 0$ & $0 \cdot 0$ \\
\hline $150 \mu \mathrm{g} / \mathrm{kg}$ & 33 & 3.0 & 16 & $0 \cdot 0$ & $100 \cdot 0$ & $0 \cdot 0$ \\
\hline $200 \mu \mathrm{g} / \mathrm{kg}$ & 30 & $3 \cdot 3$ & 20 & $5 \cdot 0$ & $95 \cdot 0$ & $0 \cdot 0$ \\
\hline \multicolumn{7}{|c|}{ Retinal pigment epithelium atrophy } \\
\hline Placebo & 35 & $11 \cdot 4$ & 13 & $0 \cdot 0$ & $76 \cdot 9$ & $23 \cdot 1$ \\
\hline $100 \mu \mathrm{g} / \mathrm{kg}$ & 36 & 0.0 & 13 & 0.0 & $100 \cdot 0$ & $0 \cdot 0$ \\
\hline $150 \mu \mathrm{g} / \mathrm{kg}$ & 30 & 0.0 & 19 & 0.0 & $100 \cdot 0$ & $0 \cdot 0$ \\
\hline $200 \mu \mathrm{g} / \mathrm{kg}$ & 37 & $0 \cdot 0$ & 13 & $0 \cdot 0$ & $100 \cdot 0$ & $0 \cdot 0$ \\
\hline \multicolumn{7}{|c|}{ Retinal deposits } \\
\hline Placebo & 36 & $19 \cdot 4$ & 12 & $8 \cdot 3$ & $83 \cdot 3$ & $8 \cdot 3$ \\
\hline $100 \mu \mathrm{g} / \mathrm{kg}$ & 41 & $12 \cdot 2$ & 8 & $0 \cdot 0$ & $100 \cdot 0$ & $0 \cdot 0$ \\
\hline $150 \mu \mathrm{g} / \mathrm{kg}$ & 43 & $14 \cdot 0$ & 6 & 0.0 & $83 \cdot 3$ & $16 \cdot 7$ \\
\hline $200 \mu \mathrm{g} / \mathrm{kg}$ & 44 & $2 \cdot 3$ & 6 & $16 \cdot 7$ & $83 \cdot 3$ & $0 \cdot 0$ \\
\hline
\end{tabular}

Note: Three cases in the $150 \mu \mathrm{g} / \mathrm{kg}$ and one case in the $200 \mu \mathrm{g} / \mathrm{kg}$ group did not have photographs before being treated and were excluded. They had no fundus abnormalities on clinical examination.

placebo in 200 patients with moderate to severe onchocerciasis from a forest area. The detailed systemic findings are presented in another report, ${ }^{19}$ which concluded that the acute systemic reactions were less with the 100 and $150 \mu \mathrm{g} / \mathrm{kg}$ than with

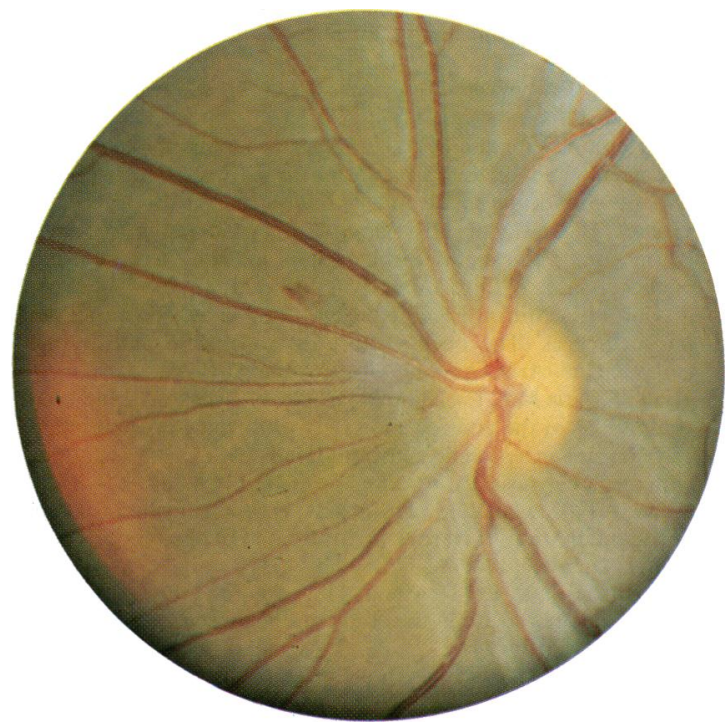

Fig. 8 Fundus photograph of 12-year-old male patient who received placebo showing a retinal haemorrhage at three months which had resolved at the six-month examination. the $200 \mu \mathrm{g} / \mathrm{kg}$ dose. Overall the reduction in skin microfilariae counts in each treatment group was comparable, though at three months there were more skin-snip positive patients in the $100 \mu \mathrm{g} / \mathrm{kg}$ group. ${ }^{19}$ From these observations it would appear that 150 $\mu \mathrm{g} / \mathrm{kg}$ is the preferred dosage in terms of both safety and microfilaricidal effect. No direct macrofilaricidal effect has been observed with ivermectin. ${ }^{15} 161819$

In the studies reported so far information on a total of fewer than 100 patients treated with ivermectin has been presented, and patients with severe ocular disease have not been treated. In our study 200 patients were selected on the basis of moderate to severe levels of infection; all had skin-snip counts greater than 12 and ranging up to 158 microfilariae per $\mathrm{mg}$. Moreover, in this study 42 patients had severe ocular disease by criteria suggested by the World Health Organisation. ${ }^{22} 23$ Of these, 30 were treated with ivermectin and none showed deterioration of their ocular status. Significantly there were no new cases of optic neuritis or optic atrophy in any person in any treatment group throughout the study. A single patient with optic neuritis was treated with ivermectin, and she improved clinically, though of course she also received intensive topical treatment. It was not possible to document a change on either fundus photographs or fluorescein angiography for this patient because of the media opacities associated with her severe uvietis.

New chorioretinal changes were seen in colour fundal photographs of patients from all four groups during the study. It is assumed that these are in fact new lesions, though it is possible that some may have been overlooked at one or other of the examinations. It is in part because of the frequent occurrence of these chorioretinal changes, observed in previous trials,${ }^{517}$ that it was considered necessary to include a placebo treated control group. Previous trials had also included fluorescein angiography to compare the chorioretinal changes after treatment with DEC, ivermectin, and with placebo. ${ }^{172} 25$ While fluorescein angiographic changes were seen in patients treated with ivermectin, similar changes were also noted in the DEC and placebo treated patients. However, no functional ocular deficiency occurred in ivermectin treated patients. It was therefore decided not to include fluorescein angiography in the present study because of the logistic problems associated with examining and treating 200 patients under field conditions.

It is noteworthy that pre-existing intraretinal pigment and retinal pigment epithelial abnormalities became worse during the study in a number of placebo patients. In addition, in a small number of placebo patients with normal fundi on entry into the study RPEA changes appeared during the study. The 
aetiology of these pigmentary and atrophic changes is still not clear, though they may be related either directly or indirectly to the presence of intraocular microfilariae. ${ }^{26}$ The reduction of intraocular microfilariae with ivermectin treatment would be expected to reduce, if not prevent, the appearance of new chorioretinal changes, and those that involve a permanent structural change should not improve. Retinal deposits appeared in a number of patients who had normal fundi on entry into the study. In addition, in a small number of patients pre-existing retinal deposits disappeared. These changes occurred in both placebo and ivermectin treated patients. We do not know if this appearance and disappearance of deposits represents the effect on the retina which results from passage of microfilariae through the retina or focal areas of inflammation akin to corneal punctate opacities around a dead microfilaria.

Overall the incidence and severity of the inflammatory reaction which could be ascribed to treatment with ivermectin were less than would be expected with the other microfilaricidal drugs such as DEC. ${ }^{5172}$ The reason for this is unknown. One factor may be that ivermectin treatment does not mobilise microfilariae in the way that DEC does. ${ }^{517}$ Ivermectin clearly has a direct effect on microfilariae, producing a spastic paralysis as shown by the altered motility of microfilariae in the anterior chamber and in vitro. ${ }^{2 k}$ This is consistent with its Gaba agonist-like activity. ${ }^{29.30}$

In this study ivermectin did not precipitate major ocular complications and may in fact have decreased the rate of progression of ocular onchocerciasis. Further, this study suggests that the drug can be used in patients with severe ocular disease without danger of the sight threatening complications associated with treatment with diethylcarbamazine. Although the results of other clinical trials in areas of savanna onchocerciasis are needed, the results of the present study in a rain forest area clearly suggest that ivermectin may ultimately prove to be sufficiently safe for use in community based mass treatment programmes.

This study was supported by grants from the Onchocerciasis Chemotherapy Project of the FAO/UNDP/World Bank/WHO Onchocerciasis Control Programme in the Volta River Basin area; by Merck Sharp and Dohme Research Laboratories, Rahway, NJ; by Uniroyal Inc., Middlebury, CT; and by NIH grants EY 03318 and AI 15351 .

We thank the following persons for their assistance: John Boateng, MB BS, and the staff of the Liberian Agricultural Company, Grand Bassa County, under the direction of Kenneth D Gerhart; S Vaani Freeman, MD, J Maxwell, MD, O V Cassell, and the staff of the LAMCO Hospital, Buchanan, Liberia; Aloysius P Hanson, PhD, and Betsy Brotman, the Liberian Institute for Biomedical Research, Robertsfield; Shirley Johnson, Alice Flumbaum, and Inga Jackman, the Johns Hopkins University,
Baltimore: Theo Greene, Ngawa Whitc, Mark Wicland. MD, and Patrick S Moore. MD. the Divison of Geographic Medicine. Department of Medicine. Case Western Reserve University. University Hospitals, Cleveland.

\section{References}

1 Mazzotti L. Posibilidad de utilizar como medio diagnostico auxiliar en la oncocercosis las reacciones alergicas consecutivas a la administracion del Hetrazan. Rev Inst Salud Enferm Trop 1948: 19: $235-7$.

2 Ikejiani $\mathrm{O}$. Studies in onchocerciasis (III). The combined use of Hetrazan and Antrypol (suramin BP) in the treatment of African onchocerciasis. West Afr Med J 1954; 3: 166-8.

3 Anderson J, Fuglsang H. Marshall TFdeC. Effects of dicthylcarbamazine on onchocerciasis. Tropenmed Parasitol 1976; 27: 263-78

4 Anderson J, Fuglsang H. Further studies on the treatment of ocular onchocerciasis with diethylcarbamazine and suramin. $\mathrm{BrJ}$ Ophthalmol 1978; 62: 450-7.

5 Bird AC, El Sheikh H, Anderson J, Fuglsang H. Changes in visual function and in the posterior segment of the eye during treatment of onchocerciasis with dicthylcarbamazine citrate. $\mathrm{BrJ}$ Ophthalmol 1980; 64: 191-200.

6 Taylor HR, Greene BM, Langham ME. Controlled clinical trial of oral and topical diethylcarbamazine in treatment of onchocerciasis. Lancet 1980; i: 943-6.

7 Goodwin LG. Recent advances in research on filariasis: chemotherapy. Trans $R$ Soc Trop Med Hyg 1984; 78 (suppl): 1-8.

8 Taylor HR. Recent developments in the treatment of onchocerciasis. Bull WHO 1984; 62: 509-15.

9 Greene BM. Onchocerciasis. In: Warren KS, Mahmoud AAF, eds. Tropical and geographical medicine. New York: McGrawHill, 1984: 419-20.

10 Anderson J, Fuglsang H, Marshall TFdeC. Effects of suramin on ocular onchocerciasis. Tropen Med Parasitol 1976; 27: 279-96.

11 Aziz MA, Diop IM, Diallo S, Lariviere M, Porta M. Efficacy and tolerance of ivermectin in human onchocerciasis. Lancet 1982; ii: 171-3.

12 Aziz MA, Diallo S, Lariviere M, Diop IM, Porta M, Gaxotte P. Ivermectin in onchocerciasis. Lancet 1982; ii: 1456-7.

13 Anonymous. Ivermectin in onchocerciasis. Editorial. Lancet 1984 ; ii: 1021.

14 Couland JP, Lariviere M, Aziz MA, et al. Ivermectin in onchocerciasis. Lancet 1984; ii: 526-7.

15 Lariviere M, Vingtain P, Aziz MA, et al. Double-blind study of ivermectin and diethylcarbamazine in African onchocerciasis patients with ocular involvement. Lancet 1985 ; ii: 174-7.

16 Greene BM, Taylor HR, Cupp EW, et al. Comparison of ivermectin and diethylcarbamazine in the treatment of onchocerciasis. N Engl J Med 1985; 313: 133-8.

17 Taylor HR, Murphy RP, Newland HS, et al. Treatment of onchocerciasis. The ocular effects of ivermectin and diethylcarbamazine. Arch Ophthalmol 1986; 104: 863-70.

18 Diallo S, Aziz MA, Lariviere M, Diallo JS, et al. A double-blind comparison of the efficacy and safety of ivermectin and diethylcarbamazine in a placebo controlled study of Senegalese patients with onchocerciasis. Trans $R$ Soc Trop Med 1986; 80: 927-34.

19 White AT, Newland HS, Taylor HR, et al. Controlled trial and dose-finding study of ivermectin for treatment of onchocerciasis. J Infect Dis 1987: 156: 463-70.

20 Keyvan-Larijani E, Newland HS, Taylor HR. An ocular reaction index for use in the study of onchocerciasis. Trop Med Parasitol 1985; 36: 241.

21 Armitage P. Statistical methods in medical research. Oxford: Blackwell, 1971: 116-26.

22 Report of WHO Expert Committee. Epidemiology of onchocerciasis. Techn Rep Ser 1976; 597: 18.

23 Taylor HR. Onchocerciasis. In: Duane TD, ed. Duane's Clinical Ophthalmology. Philadelphia: Harper and Row, 1985; 5: 62-9. 
24 Awadzi K, Dadzie KY, Schulz-Key H, Haddock DRW, Gilles HM, Aziz MA. The chemotherapy of onchocerciasis X. An assessment of four single dose treatment regimes of MK 933 (ivermectin) in human onchocerciasis. Ann Trop Med Parasitol 1985; 79: 63-78.

25 Awadzi K, Dadzie KY, Schulz-Key H, Gilles HM, Fulford AJ, Aziz MA. The chemotherapy of onchocerciasis XI. A doubleblind comparative study of ivermectin, diethylcarbamazine and placebo in human onchocerciasis in Northern Ghana. Ann Trop Med Parasitol 1986; 80: 433-42.

26 Taylor HR, Newland HS, White AT, Keyvan-Larijani E, Murphy RP, Greene BM. Onchocercal chorioretinitis: risk factor analysis in a Liberia population. Joint Meeting of the American Society of Tropical Medicine and Hygiene and the American Society of Tropical Veterinary Medicine, Miami, Florida 1985: 294.
27 Taylor HR, Greene BM. Ocular changes with oral and transepidermal therapy of onchocerciasis. BrJ Ophthalmol 1981; 65: 494-502.

28 Soboslay PT, Newland HS, White AT, Erttmann KD, Albicz EJ, Taylor HR. Ivermectin effect on microfilariac of $O$. volvulus after a single oral dose in humans. Trop Med Parasitol 1987; 38: $8-10$.

29 Campbell WC, Fisher MH, Stapley EO, Albers-Schonberg G, Jacob TA. Ivermectin: a potent new antiparastic agent. Science 1983; 221: 823-8.

30 Terada M, Ishii AI, Kino H, Sano M. Angiostrongylus cantonesis: paralysis due to avermectin $\mathrm{B}_{1}$ a and ivermectin. Exp Parasitol 1984; 57: 149-57.

Accepted for publication 4 June 1987. 